IZA DP No. 7306

Transactions Costs and the Employment Contract in the US Economy

W. Bentley MacLeod

Daniel Parent

March 2013 


\title{
Transactions Costs and the Employment Contract in the US Economy
}

\author{
W. Bentley MacLeod \\ Columbia University \\ and IZA \\ Daniel Parent \\ HEC Montreal \\ Discussion Paper No. 7306 \\ March 2013 \\ IZA \\ P.O. Box 7240 \\ 53072 Bonn \\ Germany \\ Phone: +49-228-3894-0 \\ Fax: +49-228-3894-180 \\ E-mail: iza@iza.org
}

Any opinions expressed here are those of the author(s) and not those of IZA. Research published in this series may include views on policy, but the institute itself takes no institutional policy positions. The IZA research network is committed to the IZA Guiding Principles of Research Integrity.

The Institute for the Study of Labor (IZA) in Bonn is a local and virtual international research center and a place of communication between science, politics and business. IZA is an independent nonprofit organization supported by Deutsche Post Foundation. The center is associated with the University of Bonn and offers a stimulating research environment through its international network, workshops and conferences, data service, project support, research visits and doctoral program. IZA engages in (i) original and internationally competitive research in all fields of labor economics, (ii) development of policy concepts, and (iii) dissemination of research results and concepts to the interested public.

IZA Discussion Papers often represent preliminary work and are circulated to encourage discussion. Citation of such a paper should account for its provisional character. A revised version may be available directly from the author. 
IZA Discussion Paper No. 7306

March 2013

\section{ABSTRACT \\ Transactions Costs and the Employment Contract in the US Economy}

In this paper we adapt the model of MacLeod (2007) to provide one way to formally implement some of Williamson's ideas regarding the effect of transactions costs upon employment relationship. We then explore the empirical implications of this model with a data set that measures job characteristics using the Dictionary of Occupational Titles (DOT), and merge this data set with the Panel Study on Income Dynamics (PSID). We find that viewing the data through the lens of transactions costs economics provide a useful way to organize the data on compensation in the US labor market.

JEL Classification: J33

Keywords: compensation, transactions costs, labor markets

Corresponding author:

W. Bentley MacLeod

Department of Economics

Columbia University

420 West 118th, MC 3308

New York, NY 10027-7296

USA

E-Mail: bentley.macleod@columbia.edu

\footnotetext{
* The authors would like to thanks Thomas Hubbard, Paul Oyer and the other participants at the Conference in Honor of Oliver E. Williamson. Xing Xia provided excellent research assistance. We are responsible for all remaining errors.
} 


\section{Introduction}

In a seminal paper Williamson et al. (1975) show that transactions costs considerations can help explain the choice between labor contract modes. Yet, despite the enormous influence of transactions costs economics there has been surprisingly little work done on the important question of the broad determinants of contract form, and their relevance for economic performance. This paper builds upon MacLeod and Parent (1999) to explore the transaction costs determinants of compensation form, and how this affects the level of idiosyncratic exchange.

The standard model of employment builds upon the work of Mincer (1958) and Becker (1962) (done while both were professors at Columbia University). The key ingredient is that workers can be viewed as capital goods that produce a stream of services that are priced in a competitive market. Wages vary to reflect variations in ability and investment into human capital (see Card (1999)). This perspective has been extraordinarily useful in providing a way to characterize broad trends in labor markets.

However, it is also the case that the hiring, evaluation and reward of employees is a difficult task. There is a long tradition of attempting to find the "silver bullet" that will ensure efficient supply of labor services. The classic work of Taylor (1911) observed that in many cases both the firm and worker would be better off with a compensation system that rewarded additional effort by the worker. In a classic paper, Steven Kerr (1975) provides a number of examples of firms that introduce performance pay, only to find that it gives rise to dysfunctional behavior in the organization.

Holmström and Milgrom (1991) is often cited in conjunction with the Kerr paper because it provides an elegant extension of the principal agent model to the problem of task allocation. The prediction is that agents will choose activities with the highest returns. This was the motivation for Taylor's recommendation that work be more closely monitored and rewarded. An explicit assumption of the Holmstrom-Milgrom model is that principals will anticipate how agents will respond, and hence situations, such as those described by Kerr, could not occur (he has several examples of organizations selecting rewards systems that result in agents responding in ways that the principal did not expect).

We still do not have a completely satisfactory explanation for this phenomenon ${ }^{1}$ However, Williamson (1985)'s concept of opportunism as "self-interest with guile" is possibly the best informal description of the problem. "Guile" corresponds exactly to actions that the

\footnotetext{
${ }^{1}$ See Gibbons (1997), Prendergast (1999) and Prendergast (2002) for a discussion of why agency theory does not provide an adequate theory of incentives for individuals. Though see Slade (1996) for a seminal application of the multi-task model to industrial organization. See also Lafontaine and Slade (2011) for a discussion of how agency theory and transactions cost economics have been applied to "business to business" contracts.
} 
principal would not anticipate when designing an incentive contract. One reason this occurs is because, as Williamson et al. (1975) emphasizes, worker-firm relationships are idiosyncratic, and hence the appropriate governance structure needs to be selective as a function of these idiosyncratic features. MacLeod and Parent (1999) empirically explore these ideas by matching the Quality of Employment Survey (QES), carried out in 1973-77, with data from nationally representative samples of US workers. We then relate the measures of job characteristics to the form of compensation.

In this paper we extend this work in two directions. First, we adapt the model of MacLeod (2007) to provide one way to formally implement some of Williamson's ideas regarding the employment relationship. We then explore the empirical implications of this model with a data set that measures job characteristics using the Dictionary of Occupational Titles (DOT), and merge this data set with the Panel Study on Income Dynamics (PSID). Not only is this data more recent that the data we used in MacLeod and Parent (1999), but the DOT has become the standard data used for measuring the skill content of jobs (see Autor et al. (2003)).

This approach is motivated by the constraints imposed via the use of legal instruments to secure performance (see Kornhauser and MacLeod (2012)). That model builds upon Williamson (2002)'s idea of forbearance within the firm-many actions or obligations within the firm cannot be explicitly contracted upon. Rather, it is up to the firm to voluntarily evaluate and reward the individual. It is easy to see how from a legal point of view employment is different from sales.

Consider workers at a nuclear plant. If their services were offered under a sales contract, and their inattention resulted in a nuclear accident, then under both tort and contract law the suppliers of the services would be liable for the accident. Clearly, a typical nuclear plant worker could not possibly compensate those who are harmed in such a case. Rather, the worker is typically employed by a large company that would be responsible for any losses due to an accident. In turn, the company has the right to set work conditions, monitor the workers and reward them as a function of their observed performance.

However, there is another important class of employment relationships that we simply call "complex exchange". This corresponds to cases where the performance cannot be clearly specified in advance. For example, a person engaged in R\&D, software development, or film production cannot certify the quality of the good to be produced in advance. We view this as a transaction cost that has a number of empirical implications, including the use of bonus pay to reward good performance, and lower turnover that gives rise to higher levels of relation specific investments.

The final part of the paper uses these ideas to explore the implications for compensation 
practices in the US. Ackerberg and Botticini (2002) observe that when trying to explain employee compensation (or in the case of agricultural contracts for tenants in Renaissance Tuscany) one has to control for the endogeneity of match formation. Some workers may simply prefer bonus pay, and hence it may be individual characteristics, rather than transactions costs that explain observed forms. We address this issue by looking at how job characteristics change for a worker over the course of his career. In our data we observe workers move between jobs with different characteristics. We ask whether these changes are associated with variations on compensation form, where fixed wage jobs are associated with a normal service, while salary and bonus pay jobs indicate complex exchanges.

We also look for evidence of job-specific rents. In Lemieux et al. (2009) we study the extent to which compensation form affects wage inequality and find that all of the increase in wage inequality in the top quintile of the distribution between the late 1970's and early 1990's can be attributed to the use of performance pay. This can be due to more efficient matches, or rents that accrue to workers in bonus pay jobs. Surprisingly we find little evidence of rents going to the worker, except possibly in the case of fixed wage jobs. The latter result is consistent with the implication that for normal services the threat of dismissal is used to ensure performance. We also look at the relationship between contract form and turnover. Here we find, consistent with Lemieux et al. (2012), that workers engaged in complex exchanges are less likely to suffer job loss over the business cycle. This suggests that these matches are more valuable, consistent with a great degree of relation-specific investment, a key ingredient in Williamson et al. (1975).

\section{A Model on the Link Between Transactions Costs and Contract Form}

In this section, we introduce a simple model that illustrates the interplay between transactions costs, modes of governance and legal rules. The model extends MacLeod (2007) to allow for endogenous turnover and investment, and how they are related to transactions costs. It includes as a special case the well known efficiency wage model of Shapiro and Stiglitz (1984). We begin with a description of the worker environment as a function of transactions costs. We consider an environment in which the firm and worker make specific investments $I$ and $i$ in the first period, and then trade repeatedly until they decide to separate. The investment $I$ is interpreted as worker training that is a prerequisite to have a productive worker. The investment $i$ generates a flow utility to the worker of $u^{s}(i)>0$ that is strictly concave in investment. This corresponds to moving closer to one's place of work, 
making friends at work, and any other investment activity that makes employment with this firm more valuable. In addition to these investments, we consider a number of transactions costs.

The first transactions cost is the number of times trade/contracting can occur in a period. The frequency of trade affects two countervailing forces. The first is the less frequent is trade, then the larger the potential costs from breach by one party, and the longer before damages can be assessed. The second is in terms of information. The longer the period, the more accurate the information regarding performance.

Let $\Delta>0$ denote the length of time for a single transaction, then the frequence of trade is given by $f=\frac{1}{\Delta}$. We follow Abreu et al. (1991), and suppose that the flow of benefits and costs, as well as the flow of information, remains fixed, thus increasing $f$ decreases the value of a single transaction as well as the amount of information regarding the quality of the good. This allows one to explore the effect of changing the arrival time of information while holding the value of trade per period fixed.

During the period of length $\Delta$ the worker selects effort $q \in[0,1]$. Effort is normalized to be between zero and one so we can interpret effort as a probability whenever convenient. As a matter of convention, $q=0$ denotes low effort, while $q=1$ denotes high effort. The flow cost of effort to the worker is $c(q)$, where $c, c^{\prime}, c^{\prime \prime}>0$ and $c(0)=0$. Effort determines the two potential outcomes.

The first outcome is a bad outcome resulting in a harm of $L \geq 0$. This would correspond to jobs where the worker is supposed to be attentive - say driving a bus or aircraft, or monitoring a generating facility. In these cases good performance means avoiding an accident. The probability of an accident is given by $\lambda_{b}(q, \Delta)$, with the property that $\partial \lambda_{b} / \partial q<0$. Our assumption that the quality of information does not change with the frequency of exchange implies that the likelihood of an accident should decrease with the length of period. We suppose that this probability can be approximated by a Poisson process and let:

$$
\lambda_{b}(q, \Delta)=\gamma_{b}(q) \Delta
$$

where $\gamma_{b}(q)>0$ is a Poisson parameter satisfying $\gamma_{b}^{\prime}<0, \gamma_{b}^{\prime \prime}>0$.

If one sets $\gamma_{b}(1)=0$, and $\gamma_{b}(0)>0$, then this corresponds exactly to the efficiency wage model of Shapiro and Stiglitz (1984). In that case, if the worker chooses high effort $(q=1)$ then the bad event never occurs. When the worker shirks, $(q=0)$ then the bad event follows a Poisson process. This model is rather restrictive for two reasons. First, even when a worker does not shirk, in practice adverse events may occur. Second, the model is most appropriate for what MacLeod (2007) calls a normal good. These are goods for which 
spot market transactions are appropriate-most of the time the good supplied has the proper quality, but sometimes there is a failure. For consumer goods possible failures are remediated with warranties.

There are two features of the employment contract that distinguish it from a consumer good. The first is that there may be significant relation-specific investments that make a long term relationship optimal. We shall model this by supposing that a firm must pay a cost $I$ for training new workers. Second, accidents in the employment context can easily give rise to costs that are far beyond what a worker can pay. For example, pilot error may lead to an aircraft or ship to crash, resulting in losses that the pilot could not possibly pay. This can explain why the pilot is employed by a firm, that is in turn liable and able to insure against these losses. In that case, as is discussed in more detail below, the strategy of paying a high wage to deter shirking will no longer be optimal.

The second outcome corresponds to an infrequent good outcome. This might be the sale of a good or the invention of a new idea. It is the opposite of the bad outome. Over short periods of time good outcomes are very unlikely, while they become more likely over longer periods. In this case we suppose that the value of the good outcome is $G>0$, which occurs with probability:

$$
\lambda_{g}(q, \Delta)=\gamma_{g}(q) \Delta
$$

where $\gamma_{g}$ with the Poisson parameter which satisfies $\gamma_{g}^{\prime}>0, \gamma_{g}^{\prime \prime}<0$.

Second, for some types of complex services it is the good outcome, rather than the bad outcome that is relatively rare. For example, consider research and development activities that lead to industrial patents. For such services, effort is typically unsuccessful in any period, with good outcomes occurring only once in a while. We call this a complex service that entails being supplied via complex exchange. In those cases, it is assumed that when there is a good outcome there is a capital gain of $G>0$. This outcome is generated by a Poisson process satisfying $\lambda_{g}(q, \Delta) \simeq \gamma(q) \Delta$. In this case the Poisson parameter satisfies $\gamma(0)=0, \gamma^{\prime}(q)>0, \gamma^{\prime \prime}(q)<0$ for all $q \in[0,1]$.

Payoffs can be expressed in either flow or stock terms, depending on which provides the most convenient expression. Flow terms are in lowercase, while stock terms are in upper case. We can summarize the discounted payoff from trade in period $t$ for the firm and worker as follows:

$$
\begin{aligned}
\text { Firm: } & \Pi_{t}=d(\Delta)\left(v_{t}-w_{t}\right)-B_{t}+\lambda_{g}\left(q_{t}, \Delta\right) G-\lambda_{b}\left(q_{t}, \Delta\right) L+\delta \Pi_{t+1} \\
\text { Worker: } & U_{t}=d(\Delta)\left(w_{t}-c\left(q_{t}\right)+u^{s}(i)\right)+B_{t}+\delta U_{t+1},
\end{aligned}
$$

where $\delta=e^{-r \Delta}$ is the one period discount factor and $d(\Delta)=\frac{(1-\delta)}{r}$ is the discounted value of 
one period of flow returns. We assume that the length of a period is sufficiently small that the discount factor plays little role, and thus we can simplify the expressions by using the first Taylor series term: ${ }^{2}$

$$
d(\Delta) \cong \Delta
$$

The term $v_{t}$ is the flow return from the services provided by the worker-in general these may vary due to business cycle fluctuations. To simplify matters we suppose that the flow payoffs are i.i.d. $\log$ normal distributions, where $v_{t}$ has a mean of $\bar{v}$ and variance $\sigma_{v}^{2}$. The flow wage is given by $w_{t}$. The firm can also pay a bonus of value $B_{t} \geq 0$ in any period. Should the firm dismiss the worker to hire a replacement it is assumed that the training cost $I$ is incurred.

It is assumed that the market is perfectly competitive, with the firm's outside option if no worker is hired set to $\Pi^{0}=0$. The flow utility from leaving a job in period $t$ is denoted by $u_{t}$ with mean $\bar{u}$ and variance $\sigma_{u}^{2}$. Hence we have the worker's outside option:

$$
U_{t}^{0}=u_{t} \Delta+\delta \bar{u} / r
$$

Under these assumptions, there will always be a positive probability that there should be separation and employment each period.

In summary, all the functions are taken as given. The vector of parameters that describes the physical characteristics of the relationship is given by:

$$
x=\{\Delta, L, G, I\}
$$

A paradigm normal service is given by $L>0$ and $G=0$, while a complex service is given by $L=0$, and $G>0$. In addition, there are the time varying parameters:

$$
z_{t}=\left\{v_{t}, u_{t}\right\}
$$

The timing of the model is as follows. In period zero, the firm and worker decide whether there is a match or not, and then make their investments $I$ and $i$. This decision is given by firm's investment decision $I_{0} \in\{0, I\}$, where $I_{0}=I$ indicates employment. After that we have the following sequence of decisions in periods $t=1,2, \ldots$ :

- Period t.1: The firm privately observes $v_{t}$ and worker privately observes $u_{t}$.

- Period t.2: Parties decide to continue or terminate their relationship based upon the

\footnotetext{
${ }^{2}$ One can easily verify that this approximation works well for small $\Delta$. Notice that if $u$ is a flow term, then with this approximation we have the dynamic equation $U=u \Delta+\delta U$, which implies $U=\frac{\Delta}{1-\delta} u$, and that $\lim _{\Delta \rightarrow 0} \frac{\Delta}{1-\delta} u=u / r$, which is the correct equation for the relationship between a flow and stock.
} 
new information and the history of the relationship. This results in $e_{t} \in\{0,1\}$

- Period t.3: The worker privately chooses effort $q_{t} \geq 0$.

- Period t.4: The good and bad outcomes are observed by both parties.

- Period t.5: The firm pays a wage, $\Delta \times w_{t}$ and a bonus $B_{t} \geq 0$. The bonus is assumed to be non-contractible.

The endogenous real variables are whether or not there is employment, indicated by $I_{0} \in$ $\{0, I\}$, the worker's investment $i$, the employment continuation outcome, $e_{t} \in\{0,1\}$ and effort by the worker, $q_{t} \in[0,1]$. Let $y_{0}=\left\{I_{0}, i\right\}$, and $y_{t}=\left\{e_{t}, q_{t}\right\}$ denote the endogenous outcome of the model for $t=0,1,2 \ldots$ The price terms, $c_{t}=\left\{w_{t}, B_{t}\right\}$, are determined by the contract in place that we denote by $C$. In the next subsection we derive the efficient allocation, and then work out the allocations as a function of the contracting modes.

\subsection{Efficient Allocation}

Since the worker and the firm are risk neutral, the efficient allocation is the one that maximizes the net social surplus found by adding profits to utility. Since effort does not affect future returns, it can be determined period by period. Next is the matching rule that has to be determined simultaneously with the level of relation-specific investment by the worker. Finally, wages can be set so that both parties prefer employment whenever it is efficient.

The value of effort in each period is given by:

$$
V(q, \Delta)=\gamma_{g}(q) \Delta G-\gamma_{b}(q) \Delta L-d(\Delta) c(q)
$$

Our assumptions ensure that $V_{q q}<0$, and hence there is a unique solution to:

$$
q^{*}(\Delta)=\max _{q \in[0,1]} V(q, \Delta)
$$

Since the objective function is strictly concave, then we know there is a unique solution. It is completely characterized by the following conditions. If $V_{q}(0, \Delta) \leq 0$, then $q^{*}(\Delta)=0$. If $V_{q}(1, \Delta) \geq 0$ then $q^{*}(\Delta)=1$. If neither case holds, then $q^{*}(\Delta)$ is the unique solution to:

$$
V_{q}\left(q^{*}(\Delta), \Delta\right)=0
$$

Notice that we can do the analysis in terms of flows:

$$
v(q, \Delta)=V(q, \Delta) / \Delta=\gamma_{g}(q) G-\gamma_{b}(q) L-d(\Delta) c(q) / \Delta .
$$


Also $\lim _{\Delta \rightarrow 0} v(q, \Delta)=\gamma_{g}(q) B-\gamma_{b}(q) L-c(q)$, and hence for frequent exchange the optimal effort solves:

$$
\lim _{\Delta \rightarrow 0} q^{*}(\Delta)=q^{*}=\operatorname{argmax}_{q \in[0,1]} \gamma_{g}(q) G-\gamma_{b}(q) L-c(q) .
$$

We shall suppose that exchange is relatively frequent compared to the discount rate and hence we shall use $q^{*}$ as the optimal level of effort in the subsequent analysis. When we have an interior solution, namely $q^{*} \in(0,1)$ then we have $\partial q^{*} / \partial G, \partial q^{*} / \partial L>0$. If either the benefit $G$ or the loss $L$ is sufficiently large then it is optimal for the worker to set $q^{*}=1$, the maximum effort level possible. This case is important when $c(1) / r<L$ or $G$, because then the cost of obtaining efficient effort may be much less than the loss incurred or the potential benefit. In those cases a firm can earn significant rents by hiring a worker and appropriately incentivizing them.

Next, the optimal matching is determined by maximizing the total surplus found by adding expressions (1) and (2) together. We suppose that $\Delta$ is small enough that we can ignore the effect of the discount rate $r$ in the flow equation. In that case, the dynamic programming equation for the value of the surplus at the beginning of period $t$ is given by:

$$
\begin{aligned}
S_{t} & =S^{*}\left(u_{t}, v_{t}, \alpha\right) \\
& =\max _{e_{t} \in\{0,1\}} e_{t}\left\{\left(v_{t}+\alpha\right) \Delta+\delta E\left\{S\left(u_{t+1}, v_{t+1}, \alpha\right)\right\}\right\} . \\
& +\left(1-e_{t}\right)\left\{u_{t} \Delta+\delta \bar{u} / r\right\}
\end{aligned}
$$

where $\alpha=v\left(q^{*}\right)+u^{s}(i)$ is the non-random component flow value of employment and $v(q)=\gamma_{g}(q) G-\gamma_{b}(q) L-c(q)$. This is the value from the relationship that is computed after the firm has made its training investment $I$, the worker has invested $i$ into the relationship, and parties have observed the outside $\left(u_{t}\right)$ and inside $\left(v_{t}\right)$ options. The first term is the return from employing the worker one period and then moving to the next period. The second term is the value of the outside option, which has a current realization of $u_{t}$ and then the future expected value is the discounted mean value $\bar{u} / r$.

In the appendix we show:

Proposition 1. There exists a unique solution to expression 3 such that $S^{*}\left(u_{t}, v_{t}, \alpha\right)$ is continuous and increasing in $u_{t}, v_{t}$ and $\alpha$.

The expected payoff before the inside and outside options are observed is defined by:

$$
S^{*}(\alpha)=E\left\{S^{*}\left(u_{t}, v_{t}, \alpha\right)\right\}
$$


This allows us to define the ex ante surplus before the investments are made:

$$
S^{0}(I, i)=-I-i+S^{*}\left(v\left(q^{*}\right)+u^{s}(i)\right) .
$$

The next step is to derive the optimal specific investment by the worker. The incentive to invest depends upon how long the worker expects the relationship to last. We can see this by first defining the probability that the relationship continues in any period:

$$
\rho^{*}(\alpha)=\operatorname{prob}\left\{\left(u_{t}, v_{t}\right) \mid v_{t}-u_{t} \geq \delta\left(\bar{u} / r-S^{*}(\alpha)\right) / \Delta-\alpha\right\}
$$

This allows us to determine just the return to the relation-specific investment. This is given by:

$$
U^{S}(i)=\rho\left(v\left(q^{*}\right)+u^{s}\left(i^{*}\right)\right)\left(u^{s}(i) \Delta+\delta U^{S}(i)\right)
$$

In order to compute the return to an investment the key ingredients are the probability of staying matched and the flow returns from the investment. This is used to compute the expected payoff from a specific investment which implies:

Proposition 2. If it is optimal for the worker to invest a positive amount, then the optimal level of specific investment by the worker is uniquely defined by:

$$
d u^{s}\left(i^{*}\right) / d i=\left(1-\delta \rho\left(v\left(q^{*}\right)+u^{s}\left(i^{*}\right)\right) \delta\right) / \Delta .
$$

Notice that increasing $i$ also increases the probability of the match continuing, but this does not add an extra first order term. The reason is that since matching is optimal, then at the margin the payoff from staying is equal to the payoff from leaving, and hence the first order effect of a change of $i$ on the probability is zero. This will not be the case when we come to the employment contract. We are now finally able to state the conditions for an optimal match.

Proposition 3. If $S^{*}\left(v\left(q^{*}\right)+u^{s}\left(i^{*}\right)\right) \geq i^{*}+I$ then it is efficient for the firm to hire the worker in period 0 . The optimal contract entails the worker selecting investment $i^{*}$ and attention/effort $q^{*}$. Employment continues until:

$$
v_{t}-u_{t}<\delta\left(\bar{u} / r-S^{*}\left(v\left(q^{*}\right)+u^{s}\left(i^{*}\right)\right) / \Delta-v\left(q^{*}\right)-u^{s}\left(i^{*}\right) .\right.
$$

Separation eventually occurs with probability one.

This proposition follows directly from the definition of the surplus from the match. Separation eventually occurs because the distributions of the inside options are bounded below 
and unbounded above (they are log normal), hence regardless of the value of the surplus, one has $\rho\left(v\left(q^{*}\right)+u^{s}\left(i^{*}\right)\right)<1$. The optimum illustrates the idea that all relationships need to take into account the possibility of separation. The level of investment into a relationship is a decreasing function of the probability of separation.

Notice as well that as the length of a period falls, then the $S^{*} / \Delta$ term in expression 5 increases without bound. This implies that in this model with iid shocks, if the shocks are short lived, then once a relationship starts, the duration of the relationship is longer. Essentially, any individual shock is of less importance, and hence the relationship becomes

more durable. In terms of transactions costs economics, a large $\Delta$ implies a lumpy, or large transaction that has a lower probability of continuing after parties have completed the first period.

\section{Contracting Modes}

If we have complete and symmetric information with complete contracts then we would expect parties to agree to implement an efficient allocation. In practice this is not possible because contracts are incomplete. In this section we consider the issue of implementing an allocation, and how transactions costs interact with contract incompleteness. We consider separately the cases of normal and complex exchange. The usefulness of this distinction can be seen if we view the employment contract via the lens of the law.

Holmes (1897) observes that a contract is nothing more than an agreement to supply services, which if breached, implies that damages are due. We have called a good "normal" when non-performance occurs when there is a harm. This type of situation is relatively easy to deal with from a legal perspective because when the harm occurs this can be unambiguously identified with a breach of contract. In the case of consumer goods, defects are addressed via warrantee provisions in the contract. If a person is harmed, then the harmed party can appeal to tort law to obtain a remedy.

In the case of a complex good this approach does not work. When one hires a researcher to discover a new product, or one goes to a doctor to find why a person is ill, one cannot be assured of success. Namely, even if the worker is competent and diligent, they may fail to discover a new good or correctly diagnose the illness. We show that in such cases incentives can be provided via a relational contract that pays a bonus to the worker when there is a success. What is nice about these contracts relative to contracting for a normal service is that we can observe in the data whether or not a job pays a bonus.

We consider three contracting modes. The first is a spot contract that is used when performance is perfunctory and easily verifiable. Next, we consider relational contracts that 
are appropriate for normal and complex services. In the case of normal services an efficiency wage type contract is appropriate, while a bonus contract is most appropriate for a complex service. The analysis will tease out the link between the transactions costs characterizing the exchange, contract form, and the efficiency of the relationship.

\subsection{Contingent Claims Contracts}

Consider first a contingent claims contract under the hypothesis of full contractibility for one period. In this mode firms and workers re-contract each period. To simplify matters, suppose that there are no relation-specific investments, and that the firm is able to make a take it or leave it offer to the worker. For an "innovative" good there is no uncertain liability $(L=0)$, and thus the only variable compensation the firm has to consider is offering a bonus $B=G$ whenever the good outcome occurs, in addition to a contractually agreed upon wage $w_{t}$ for period $t$. This ensures the worker always selects the efficient level of effort $q^{*}$ and hence the wage would be set so that the utility of the worker in period $t$ is:

$$
U_{t}=\left(w_{t}-c\left(q^{*}\right)\right) \Delta+\gamma_{g}\left(q^{*}\right) \Delta B+\delta U_{t+1}=u_{t} \Delta+\delta U_{t+1}
$$

This implies a wage:

$$
w_{t}=u_{t}+c\left(q^{*}\right)-\gamma_{g}\left(q^{*}\right) B
$$

Since the bonus offsets the $\gamma_{g}\left(q^{*}\right) B$ term in the wage, the net cost of the worker is $u_{t}+c\left(q^{*}\right)$, and hence under such a contract employment occurs if and only if the firm obtains at least zero flow profits:

$$
\pi_{t}=v_{t}-\left(u_{t}+c\left(q^{*}\right)\right)+\gamma_{g}\left(q^{*}\right) G \geq 0
$$

This has a number of implications. The first is that we obtain efficient matching employment occurs only if the net productivity of the worker, $v_{t}-c\left(q^{*}\right)+\gamma_{g}\left(q^{*}\right) G$ is greater than the outside option, $u_{t}$. Second, wages should fluctuate from period to period with outside opportunities. There are some occupations where this is true, such as day laborers or self-employed individuals, but overall wages appear to be relatively rigid compared to outside opportunities. Third, in our model we would expect $B \gg w_{t}$, and hence we should observe bonuses that are much larger than wages. We do observe something like this in industries that use stock options, however those are long term relationships where one of the rationales for these options is to encourage workers to invest into the firm. As discussed in Lemieux, MacLeod, and Parent (2009), the median bonus represents less than 5\% of compensation, which does not correspond to the large gains that an innovation might yield 
a firm.

In the case of a normal service a worker can be induced to choose the efficient effort level by setting $B_{t}=-L$ whenever a bad outcome occurs. In this case we have:

$$
U_{t}=\left(w_{t}-c\left(q^{*}\right)\right) \Delta-\gamma_{g}\left(q^{*}\right) \Delta L+\delta U_{t+1}=u_{t} \Delta+\delta U_{t+1},
$$

and hence:

$$
w_{t}=u_{t}+c\left(q^{*}\right)+\gamma_{g}\left(q^{*}\right) L .
$$

Again, the model has the unrealistic prediction that wages fluctuate a great deal from period to period. The more problematic assumption is that the worker pays $L$ whenever there is a bad outcome. In practice the harm from a worker's action can be much larger than the current wage, which makes the contract unenforceable in practice. It is also the case that when the harm occurs to parties outside of the firm then both the firm and worker are jointly liable. These are very real limits upon the ability to contract with workers, which fits in well with Williamson et al. (1975)'s critique of Alchian and Demsetz (1972)'s claim that one can use repeated spot-market transactions to achieve efficient exchange.

Finally, the inside and outside options are rarely perfectly observed by the worker and firm respectively, and hence one must deal with the transactions cost of asymmetric information. From Myerson and Satterthwaite (1983) we know that with two-sided asymmetric information regarding flow returns and a matching condition such as 5 implies that it is impossible for parties to negotiate to an efficient outcome. In this next section we discuss how relational contracting addresses these issues.

\subsection{Relational Contracting}

Let us now consider repeated contracting over time. The first point is that since we have two-sided asymmetric information then it is impossible to write a contract that gives efficient trade in each period. Hall and Lazear (1984) point out that to solve this problem firms can fix the wage in advance, thereby avoiding the cost of idiosyncratic bargaining each period. However, they point out that this comes at the cost of excess sensitivity of quits and layoffs to business cycle fluctuations.

The fixed wage contract has an additional benefit in that it can reduce the costs associated with inefficient separation. If wages are fixed in advance for several periods then, as MacLeod and Malcomson (1993) show, this provides an incentive for the worker to make relationspecific investments. In the absence of a fixed wage, the firm would set wages equal to the worker's best estimate of the outside option, that in turn reduces the return from a relation- 
specific investment by the worker. In the next two subsections we address the design of contracts for normal and innovative employment services with the constraint that wages are fixed in advance.

Williamson's idea of forebearance is modelled by supposing that the firm has two additional instruments that do not rely upon courts for enforcement. First, they can voluntarily pay a bonus for good work. Second, they can dismiss a worker without cause should they believe performance is unsatisfactory. In the next two sections we detail the consequences of these instruments for normal and complex labor services respectively, that in turn allow us to explore observed employment contracts through the lens of transactions cost economics.

\subsubsection{Normal Labor Service}

Consider a long term contract with normal labor services, in which case $G=0$ and there is a possibility of a loss $L>0$ from accidental non-performance. It is assumed that this loss is sufficiently large that in any period the firm cannot write a binding contract to have the worker pay $L$. One might use a long term wage cut in the face of a loss, but as a general policy this is not sustainable because multiple losses would result in wages being below her alternative, and hence would not be credible. At some point dismissal would be the final penalty available to the firm.

Under such a scenario the only possibility is employment at will at a fixed wage, combined with dismissal if a loss occurs. In order for there to be a loss associated with firing it must be the case that the wage is set above the market alternative. To characterize the solution we derive the payoffs as a function of the endogenous variables $(i, q, w)$. Firm profits in state $v_{t}$ are given by:

$$
\Pi\left(v_{t}, i, q, w, \Pi^{*}, I\right)=e\left(v_{t}, u_{t}, \Pi^{*}, U^{*}\right)\left(\left(v_{t}-\gamma_{b}(q) L-w\right) \Delta+\delta \Pi^{*}-\delta \gamma_{b}(q) \Delta I\right) .
$$

The employment term $e$ is 1 if there is a match and zero otherwise. It depends upon both firm and worker states since either might choose to leave for better alternatives. In addition, if the worker is fired when a bad outcome occurs, then the firm hires a new worker at a cost $I$ in the current period, and gets the same expected return $\Pi^{*}$ in the following period. Notice that since the firm faces a loss when firing the worker to be replaced with an identical worker then this is not efficient. In order to sustain this behavior as an equilibrium MacLeod and Malcomson (1989) show that one requires a set of self-enforcing social norms with the feature that the worker shirks if she is not dismissed after an adverse event, re-inforced by the firm's promise to dismiss if there is an accident. 
The worker's utility is given by:

$$
\begin{aligned}
U\left(u_{t}, i, q, w, U^{*}\right) & =e\left(v_{t}, u_{t}, \Pi^{*}, U^{*}\right)\left(\left(w-c(q)+u^{s}(i)\right) \Delta+\delta\left(\left(1-\gamma_{b}(q) \Delta\right) U^{*}+\gamma_{b}(q) \Delta \bar{U}\right)\right) \\
& +\left(1-e\left(v_{t}, u_{t}, \Pi^{*}, U^{*}\right)\right)\left(u_{t} \Delta+\delta \bar{U}\right)
\end{aligned}
$$

The first term is the payoff if there is employment. If the bad outcome occurs, then the worker is fired. Solving for the equilibrium requires a number of steps. As in the case of the efficent matching problem, we solve for worker effort first:

$$
c^{\prime}(q)=-\gamma_{b}^{\prime}(q)\left(U^{*}-\bar{U}\right)
$$

This is a standard expression from the efficiency wage literature-the incentive to worker depends upon the effect of effort upon the probability of an accident $\left(\gamma_{b}^{\prime}\right)$ and the difference from continuing employment and leaving $\left(U^{*}-\bar{U}\right)$. By increasing the wage the firm increases this incentive, but the wage also increases the turnover rate from dismissals. In the original efficiency wage model of Shapiro and Stiglitz (1984) this turnover is exogenous. Here we extend to the case in which it is endogenous.

It is also worth highlighting the assumption that uncertainty regarding the inside and outside options are non-contractible is key to ensuring that the fixed wage is the only incentive compatible contract, as shown in Grossman and Hart (1981). This expression shows that we can write quality as an increasing function of $U^{*}: q^{*}\left(U^{*}\right)$. Observe that the current wage has NO effect on incentives. Rather, wages affect incentives because they are assumed to be constant over time. This implies that a rise in the wage raises future returns from employment, increasing the incentive to work hard in order to reduce the likelihood of dismissal. This is an efficiency wage effect that would not be present if wages were set each period equal to the market rate.

The incentives for the worker to make specific investments is still given by 4 , where $\rho$ is the probability that the worker keeps her job in equilibrium. To compute the probability in this case we solve for the employment conditions in period $t$ :

$$
\begin{gathered}
\left(\left(w-c\left(q^{*}\left(U^{*}\right)\right)+u^{s}(i)\right) \Delta+\delta\left(\left(1-\gamma_{b}\left(q^{*}\left(U^{*}\right)\right) \Delta\right) U^{*}+\gamma_{b}\left(q^{*}\left(U^{*}\right)\right) \Delta \bar{U}\right)\right) \geq\left(u_{t} \Delta+\delta \bar{U}\right) \\
\left(v_{t}-\gamma_{b}\left(q^{*}\left(U^{*}\right)\right) L-w\right) \Delta+\delta \Pi^{*}-\delta \gamma_{b}(q) \Delta I \geq 0 .
\end{gathered}
$$


Let $e\left(v_{t}, u_{t}, \Pi^{*}, U^{*}\right)=1$ if and only if these conditions hold:

$$
\begin{aligned}
& u_{t} \leq w+u^{s}(i)-c\left(q^{*}\left(U^{*}\right)\right)-\delta \gamma_{b}\left(q^{*}\left(U^{*}\right)\right)\left(U^{*}-\bar{U}\right)+\delta\left(U^{*}-\bar{U}\right) / \Delta \\
& v_{t} \geq w+\gamma_{b}\left(q^{*}\left(U^{*}\right)\right)(L+\delta I)-\delta \Pi^{*} / \Delta .
\end{aligned}
$$

Comparing 8 and 9 to the efficient matching conditon 4 one sees immediately that this contract does not give efficient matching, but results in excessive quits and layoffs, as in Hall and Lazear (1984). When we come to complex goods in the next subsection, we shall see that bonus pay may improve both performance and matching relative to an efficiency wage contract. Also notice that as the time period gets shorter $(\Delta \rightarrow 0)$, then the probability of separation falls, all else held fixed. This is quite nice, and shows that increasing the frequency of trading does not necessarily imply a shorter relationship. This is increasing in $\Pi^{*}$ and $U^{*}$ and $i$. We cannot specify the value function in terms of the probability of separation because of its correlation with the employment decision. Define the following functions:

$$
\begin{aligned}
& F^{\Pi}\left(w, \Pi^{*}, U^{*}, i, I\right)=E\left\{\Pi\left(v_{t}, i\left(\Pi^{*}, U^{*}\right), q^{*}\left(U^{*}\right), w, I, \Pi^{*}\right)\right\}, \\
& F^{U}\left(w, \Pi^{*}, U^{*}, i, I\right)=E\left\{U\left(u_{t}, i\left(\Pi^{*}, U^{*}\right), q^{*}\left(U^{*}\right), w, I, U^{*}\right)\right\} .
\end{aligned}
$$

Our assumptions ensure that the profits and utility are bounded above and below. Moreover, these functions are continuous and bounded as well, and thus we can be assured of the existence of a solution to the fixed point problem-we can ensure uniqueness by supposing that the solution with the highest profits is always selected, and hence let $\left(\Pi^{*}(w, i, I), U^{*}(w, i, I)\right)$ be the solution to:

$$
\begin{aligned}
& \Pi^{*}(w, i, I)=F^{\Pi}\left(w, \Pi^{*}(w, i, I), U^{*}(w, i, I)\right), \\
& U^{*}(w, i, I)=F^{U}\left(w, \Pi^{*}(w, i, I), U^{*}(w, i, I)\right),
\end{aligned}
$$

Given these payoffs, the worker next chooses her investment:

$$
i^{*}(w, I)=\operatorname{argmax}_{i \geq 0} U^{*}(w, i, I)-i .
$$

The effect of wages upon investment cannot in general be signed because it depends upon two countervailing effects. When $w$ is larger, the probability of dismissal is larger due to the inside option $v_{t}$. This is determined by 9 , and is independent of the positive effect of $i$ upon employment via 8, which is determined by the worker's outside offer. All we can say is that 
it is continuous. We complete the solution by solving the firm's problem:

$$
\begin{aligned}
& w^{*}(I)=\operatorname{argmax}_{w \geq 0} \Pi^{*}\left(w, i^{*}(w, I), I\right) . \\
& \text { subject to : } \\
& U^{*}\left(w, i^{*}(w, I), I\right)-i^{*}(w, I) \geq \bar{U}
\end{aligned}
$$

Thus we have:

Proposition 4. The relational contract for a normal service consists of a fixed wage $w^{*}$. Employment occurs if $\Pi^{*}\left(w^{*}, i\left(w^{*}, I\right), I\right) \geq I$. Under such a contract we have:

- Employment is at will.

- Quits and separations are higher than at the first best.

- Quits are voluntary and hence wages at new firms are equal to wages at previous firms.

- Involuntary separations, whether due to a fire or layoff, lead to a lost in utility to the worker.

The result regarding employment at will follows from assuming $L$ is not contractible, but observable by the worker and firm. If $L$ were contractible, and one could use it as the basis for a dismissal, then the firm would simply add a severance payment $S$ if the worker is dismissed without cause. This payment would be set to optimize the turnover rate separately from the incentive effect of the higher wage. The solution procedure would be exactly the same as above.

\subsubsection{Complex Service}

Next consider the case for which $L=0$ and $G>0$. This corresponds to many complex labor services where the output is either infrequent, or infrequently measured. For example, research and development departments produce services that occasionally have successes. Sales of large commodities, such as commercial real estate or when entrepreneurs are in environments where there is much work before a success is realized.

If the bonus is contractible, then the employment contract can specify a reward when $G$ is realized. In contrast to the normal service case above, this can ensure efficient production when the firm is assumed to always be solvent. Let us consider the case where it is not contractible, but observable by the worker and firm. We would then use a relational contract as in MacLeod and Malcomson (1989). 
The solution procedure will be similar to the case of a normal service, but the difference now is that the rare event is good news, and hence the firm pays a bonus $B$ whenever the good outcome $G$ is realized. This implies that the worker has a simple static optimization exercise. To ensure that the bonus is paid the worker can use the threat of a quit as an enforcement mechanism when the firm does not pay when a good event occurs. The employment decision $e\left(v_{t}, u_{t}, \Pi^{*}, U^{*}, i\right)$ is the solution to 8 and 9 with the addition of a $\gamma_{b}(q) B$ term for the worker, and the replacement of $\gamma_{b}(q) L$ with $\gamma_{g}(q) G$ for the firm. The payoff functions for the firm and worker are now:

$$
\begin{aligned}
& \Pi\left(v_{t}, i, q, w, B, \Pi^{*}\right)=e\left(v_{t}, u_{t}, \Pi^{*}, U^{*}, i\right)\left(\left(v_{t}+\gamma_{g}(q)(G-B)-w\right) \Delta+\delta \Pi^{*}-\delta \gamma_{b}(q) \Delta I\right) \\
& \begin{aligned}
U\left(u_{t}, i, q, w, B, U^{*}\right) & =e\left(v_{t}, u_{t}, \Pi^{*}, U^{*}, i\right)\left(\left(w-c(q)+\gamma_{g}(q) B+u^{s}(i)\right) \Delta+\delta\left(\left(1-\gamma_{b}(q) \Delta\right) U^{*}+\gamma_{b}(q) \Delta \bar{U}\right.\right. \\
& +\left(1-e\left(v_{t}, u_{t}, \Pi^{*}, U^{*}, i\right)\right)\left(u_{t} \Delta+\delta \bar{U}\right)
\end{aligned}
\end{aligned}
$$

With bonus pay the worker solves a static, rather than a dynamic problem:

$$
c^{\prime}(q *(B))=\gamma_{b}^{\prime}\left(q^{*}(B)\right) B .
$$

Next, one has an incentive constraint for the firm for the bonus payment. In order to enforce the bonus payment the worker has to threaten to quit should a bonus not be paid in the event of a success. Under the assumption that there are no reputation effects, then the firm will hire a new worker, and hence the cost is given by the investment in worker training. Thus we have:

$$
B \leq \delta I .
$$

This illustrates that a necessary condition for the use of bonus pay is the existence of a relation-specific investment by the firm.

We begin with the case in which the firm promises the same bonus $B$ each period. Then from an analysis similar to the one in the previous section, there exists payoffs of the form $\left(\Pi^{*}(w, B, I), U^{*}(w, B, I)\right)$, and the optimal contract solves:

$$
\begin{aligned}
\max _{w, B \in \Re_{+}^{2}} \Pi^{*}(w, B, I) & \text { subject to }: \\
U^{*}(w, B, I)-i^{*}(w, B, I) & \geq \bar{U} \\
B & \leq \delta I
\end{aligned}
$$


An interesting feature of this optimization problem is that the individual rationality constraint for the worker might not be binding. The reason for this is that worker turnover may be costly for the firm, and hence it may offer a utility above the market. This is a point first made by Hashimoto (1981). This effect is quite different from the case of a normal service. There employee utility was necessarily above the outside option in order to provide incentives for performance. In this case, the rent may exist to ensure better matching. Both cases illustrate how transactions cost and incomplete contract may lead to rents for a variety of reasons.

The continuity of payoffs in 12 ensures that a solution exists, though whether or not the worker is paid above her outside alternative depends upon the parameters of the model. We will empirically look for evidence of rents in the next section.

Proposition 5. The relational contract for a complex service consists of a fixed wage $w^{*}$ and a bonus $B^{*}$ that is paid whenever there is a good outcome. Employment occurs if $\Pi^{*}\left(w^{*}, i\left(w^{*}, I\right), I\right) \geq I$. Under such a contract we have:

- Employment is at will.

- Quits and separations are higher than at the first best.

- Quits are voluntary and hence expected wages at new firms are equal to wages at previous firms.

- Off equilibrium, quits due to non-payment of a bonus might lead to a higher income at the new firm.

- Fires are due to low realizations of $v_{t}$ and hence do not necessarily lead to a loss in utility to the worker.

Notice that in this setup separation occurs only because of the value of the match, and not because of the need to discipline the worker. Hence, if all parameters are the same and $B=L$, then we would expect layoffs to be lower in complex jobs. There is an additional difference. Suppose the worker and the firm can observe the state of the economy, say $s \in\{L, H\}$. In the $L$ state, the outside option for the worker is lower. In that case, since bonus pay is non-contractible (in contrast to the contractible wage in the normal good case), then parties could agree to lower bonuses in the $L$ state. This would entail lower effort by the worker (since the lower bonus would be agreed upon before the worker chooses effort). This would relax the individual rationality constraints and allow parties to get closer to efficient matching (full contractibility upon $\left(v_{t}, u_{t}\right)$ would allow for first best matching). This is a testable implication. 
In summary, the introduction of transactions costs leads to firms and worker choosing between various contract modes depending upon the characteristics of the service supplied by the worker. The form that the contract takes varies as a function of market alternative, relation-specific investments and the observability of performance. The three contracting modes are motivated by the Williamson considerations of transactions costs and job characteristics. In an agency setup the only consideration is the quality of information regarding worker effort. The extent to which there is variable pay varies with the worker's aversion towards risk. The previous literature, particularly Grossman and Hart (1981) and Gibbons (1997) highlight the challenges of using this model to organize the evidence on worker compensation. In the next two sections we use the ideas developed in this model to motivate an empirical investigation of contract form in the US.

\section{The Data}

In this paper we combine two data sets, one containing information about the task content of occupations, and the other containing the usual survey questions about labor market outcomes and socioeconomic characteristics such as hourly earnings, education, race, marital status, etc. The fact that those two data sets both include the Census 1970 occupation codes allows us to merge the two and assign to each individual worker task content measures associated with his occupation.

The goal of the empirical analysis is to explore the idea that employment can be viewed through the lens of transactions cost economics that divides jobs into normal and complex exchange. Normal exchange corresponds to occupations for which there is a clear performance obligation. In that case, the terms of trade can be set in advance using a fixed wage. Separation occurs if there is non-performance or it is no longer in the interests of either party to continue with the relationship. We use the Dictionary of Occupational Titles (DOT) to provide some exogenous measure of job characteristics that can be viewed as characterizing normal exchange. We can then ask if firms in which workers are in such occupations are more likely to use fixed wage contracts.

Similarly, some jobs require workers to use judgment and hence performance cannot be easily defined in advance. For those we ask if they are associated with more use of salaried compensation and bonus pay. The theory suggests that these jobs would rely more upon relation-specific investment into worker skill, and hence there should be rents upon dismissal, and a lower likelihood of a layoff during a downturn compared to normal jobs. The rest of this section describes the data we use in more detail. The following section discusses the empirical evidence. 


\subsection{The 1977 Dictionary of Occupational Titles (DOT) and its 1991 Revision}

We use the DOT to measure the characteristics of a job that, according to transactions cost theory, should affect the form of compensation used by the firm. In their paper on the link between worker skills and the task content of occupations, Autor et al. (2003) (ALM) exploit the information contained in the Dictionary of Occupational Titles (DOT) on a wide variety of occupation characteristics measured at the 4 digit level. Note that ALM use both the 1977 4th Edition version of the DOT as well as the 1991 revised 4th edition. ${ }^{3}$ Therefore it is possible to exploit variations in task content both across occupations as well as across time within occupations.

We focus on the same five measures of task content used by ALM namely non-routine manual, routine manual, non-routine cognitive-interactive, routine cognitive, and non-routine cognitive-analytical. The following table describes the task content that those five DOT variables are meant to measure (a somewhat different and more detailed description can be found in Appendix 1 of Autor et al. (2003)).

\footnotetext{
${ }^{3}$ We are grateful to David Autor for providing us with the DOT data and the supporting documentation.
} 
Table 1. Task Content Measures in the Dictionary of Occupational Titles 1977 4th Edition and 1991 Revision

\begin{tabular}{ll}
\hline DOT Variable & \multicolumn{1}{c}{ Interpretation } \\
\hline Routine Manual & Measures finger dexterity associated with e.g. \\
& mixing ingredients for recipes or packing \\
& agricultural produces. \\
& Measures the adaptability to work requiring the \\
Routine Cognitive & setting of limits or standards for example by \\
& being able to operate a billing machine or to use \\
& gauges. \\
& Measures the degree of eye-hand-foot \\
& coordination required on the job, for example \\
Non-routine Manual & when driving a bus or piloting a plane. \\
& Measures the quantitative reasoning requirements \\
& of jobs, from simply being able to add and \\
Non-routine Cognitive-Analytical & subtract to being able to perform complex \\
& mathematically-oriented analyses. \\
Measures interactive, communication, planning, \\
and managerial skills, as well as ability to \\
process and synthesize information. \\
\hline Non-routine Cognitive-Interactive
\end{tabular}

Whereas the focus in ALM is on the degree to which computers can be seen as substitutes or complements in performing those tasks, our goal is to link the task content to transactions costs affecting the way employees are paid. More complex employment relationships involving non-routine cognitive tasks should be associated with different contractual arrangements compared to jobs involving simple repetitive tasks.

Each task measure is originally coded on a continuous scale between 0 and 10, with 10 representing a more intensive use of the task. We standardize each to have a mean of zero and a standard deviation of one so that the coefficients associated with them can be seen as representing the "impact" of a one standard deviation increase on the probability that the worker is in a complex exchange job. 


\subsection{The Panel Study of Income Dynamics (1976-2004)}

The PSID sample we use consists of male heads of households aged 18 to 64 with average hourly earnings between $\$ 4.00$ and $\$ 300.00$ (in 2008 dollars) for the years 1976-2004, where we obtain the hourly wage rate by dividing total labor earnings by total hours of work, both for the previous calendar year. ${ }^{4}$ Given that we use performance pay as an identifier for complex exchange, this wage measure based on total yearly earnings is preferable to "pointin-time" wage measures that would likely miss infrequent payments (specifically bonuses) of performance pay. The self-employed are excluded from the analysis since our measure of performance pay, based on receiving bonuses, commissions, or piece-rates, is defined for employed workers only. We also exclude workers from the public sector.

This leaves us with an initial sample of 31, 276 observations for 3,283 workers. We then merge all those observations by 3-digit Census 1970 occupations to the corresponding 3-digit averages of the DOT task content variables. Since not all observations in the PSID can be matched to the corresponding DOT averages we lose 2,861 observations, which results in a sample size of 28,415 for 3,090 workers. Note that we match the 1977 DOT averages to the observations in the PSID for the years between 1976 and 1984 while we use the 1991 DOT averages for the years 1985-2004. ${ }^{5}$ All estimates reported in the paper use the PSID sample weights.

\subsubsection{Identifying Performance Pay in the PSID}

We use as our definition of "complex exchange" an indicator for whether a worker is paid either just a salary or a combination of salary and a bonus over the course of the employment relationship. Since we use bonus pay as a marker of complex exchange, we first have to describe how we identify bonus pay, as well as other forms of performance pay, in the PSID.

For all interview years we are able to determine whether a worker received a bonus or a commission over the previous calendar year through the use of multiple questions. First, workers are asked the amount of money they received from working overtime, from commissions, or from bonuses paid by the firm. ${ }^{6}$ Second, we sometimes know only whether or not workers worked overtime, not the amount of pay they received for overtime. Thus, we classify workers as not having had a variable pay component if they worked overtime. Third,

\footnotetext{
${ }^{4}$ In the PSID, data on hours worked during year $t$, as well as on total labor earnings, bonuses/commissions/overtime income, and overtime hours, are asked in interview year $\mathrm{t}+1$. Thus we actually use data covering interview years 1976-2005. Annual earnings were top coded at \$99,999 until 1982 (and not top coded since then), but only a handful of individuals were at the top code.

${ }^{5}$ Choosing another arbitrary cutoff year (say, 1991) did not make a substantive difference.

${ }^{6}$ Note that the question refers specifically to any amounts earned from bonuses, overtime, or commissions in addition to wages and salaries earned.
} 
workers not paid exclusively by the hour, or not exclusively by salary, are asked how they are paid: they can report being paid commissions, piece-rates, etc., as well as a combination of salaried/hourly pay along with piece-rates, bonuses or commissions. Through this combination of questions, we can identify all non-overtime workers who received performance pay in bonus, commission, or piece-rate form.

\subsubsection{Defining complex exchange}

Using the information on whether workers are on commission or not, we can identify those earning a bonus. We define complex exchange as employment relationships in which the worker is paid either just a salary or a combination of being paid a salary and having received a bonus at least once over the course of the employment relationship with the firm. Employment relationships in which workers are paid exclusively by the hour or through a combination of hourly pay along with commissions or on piece rates are classified as "normal" jobs. Commissions and piece rate contracts, like bonuses, are a form of variable pay. However, they are contractually agreed upon ex ante to be a function of some well defined performance measures. Hence, they are a form of contingent pay in the sense of Williamson et al. (1975).

Since we use actual payments of bonuses, commissions or piece rates to identify performancepay jobs, we are likely to misclassify performance-pay jobs as non-performance-pay jobs if some employment relationships are either terminated before performance pay is received, or partly unobserved for being out of our sample range. This source of measurement error is problematic because of an "end-point" problem in the PSID data. Given our definition of bonus pay jobs, we may mechanically understate the fraction of workers in such jobs at the beginning of our sample period because most employment relationships observed in 1976 started before 1976, and we do not observe whether or not performance pay was received prior to 1976. Similarly, jobs that started toward the end of the sample period may be performance-pay jobs but are classified otherwise because they have not lasted long enough for performance pay to be observed. We deal with that problem using a re-weighting scheme that adjusts the distribution of the number of times employment relationships are observed at either end of the sample period such that it mimics the distribution over the 1982-1990 period, when there should not be an end-point problem. More details on this re-weighting adjustment are provided in Lemieux, MacLeod, and Parent (2009).

\subsection{Summary Statistics}

In Table 2 we report sample means by type of job. Focusing first on the job characteristics, we can see that although our definition of what constitutes complex exchange results by 
necessity from an arbitrary-albeit reasonable-choice, there are large differences in the task content across both types of jobs. Complex exchange involves more direction, control, and planning of activities ("non-routine cognitive-interactive") as well as quantitative reasoning ("non-routine cognitive-analytical") than is the case in normal exchange, while the opposite is true for jobs that involve either routine tasks or non-routine manual task requirements.

Complex exchange also pays substantially more and workers in them have on average two additional years of education relative to workers in non-complex exchange jobs. The two types of jobs are also considerably different along many other dimensions. Individuals in complex exchange jobs are much less likely to be unemployed at the time of the interview and are also almost certain not to be covered by a collective bargaining agreement. They also work more hours during the year than their counterparts in normal jobs.

Looking at the differences in task content across job types, there would appear to be a robust relationship between those task content variables and being in a complex exchange job. However, it is also quite possible that workers in jobs which involve more non-routine cognitive-interactive are a selected group. In the next section we address this issue by exploiting the time variation in the DOT variables.

\section{Multivariate Analysis}

\subsection{The Effect of Job Characteristics}

In Tables 3 and 4 we estimate the relationship between the DOT characteristics and the incidence of complex exchange, controlling for observed heterogeneity. We also control for unobserved worker heterogeneity by using fixed-effect regressions, exploiting the fact that the DOT variables changed following the 1991 revision.

As mentioned above we use the values in the 1977 version for the years between 1976 and 1984, and the 1991 values for all years thereafter. Another source of variation that can be exploited is the fact that workers may change 3-digit occupations, which would imply that the DOT variables would change as well. However, it is likely that many of those occupational switches represent noise. ${ }^{7}$ To limit the extent of such false transitions, we force the occupation in an employment relationship to be the modal occupation, while not imposing any restrictions on occupational switches that happen at the same time as employer changes.

If we first look at Table 3 we can see that we easily reject the hypothesis that the DOT job

\footnotetext{
${ }^{7}$ See Mellow and Sider (1983) for evidence that 3-digit occupations are riddled with measurement error in survey data.
} 
characteristics have no effect on the probability of being observed in a complex exchange job. In columns [1] to [4] we simply estimate the cross-sectional relationship using either a linear probability model or a probit. As it turns out it does not make much difference whether we use one or the other. The estimates show a consistent pattern of a negative relationship between manual tasks-routine or not-and the complex exchange job dummy while there is a strong positive association between the non-routine cognitive-interactive variable and being in a complex exchange job (less so for the cognitive analytical component). A one-standard deviation increase in the degree to which a job requires direction, control, and planning (the non-routine cognitive-interactive variable) is associated with an increase in the probability of being in a complex exchange job of between 7.5 to $11 \%$, depending on the specification. Note that while adding occupational controls in columns [3] and [4] reduces the estimates somewhat, it does not reduce them to zero. ${ }^{8}$

As mentioned above, it is possible that selectivity is partly responsible for the estimates reported in columns [1] to [4]. To see whether this is the case, we estimate fixed-effect linear probability models whose results are reported in columns [5] and [6]. In this case, the effect of job characteristics is identified by how compensation form changes when a worker moves between jobs with different DOT characteristics. Hence, we are controlling for variations in worker skill. Two main results stand out. First, there is strong evidence of selectivity: the association between the manual task content variables and being in a complex exchange job is basically eliminated once we include occupational controls. Workers in manual tasks are systematically different than those in non-manual tasks and that difference contributed to the estimates reported in columns [1] to [4]. Second, the robust relationship between non-routine cognitive-interactive tasks and being in a complex exchange job is still there and is not much different than the one estimated in the cross-section.

In Table 4, we get very similar results if we use a restricted sample made of workers who, in each year of the employment relationship, report being paid a salary and/or receiving a bonus i.e of being in a complex exchange job as we define it every year, or neither of those. The only notable difference is that even the routine manual task content of a job is significantly related to the probability that a worker is observed in a complex exchange job.

To summarize the results shown in Tables 3 and 4, it would appear that conditional on observed and time-invariant workers characteristics, a change in the task content across employment relationships leads to a change in the nature of one's job, and associated compensation form. In particular, bonus pay jobs appear to be used to compensate workers that are supplying a complex service, as measured by the DOT task content measures.

\footnotetext{
${ }^{8}$ Of course, it would kill all the effects if we included 3-digit occupational dummies since those would absorb all the variation in the DOT characteristics.
} 
Our definition of what constitutes "complex exchange", while reasonable, is nevertheless arbitrary. In Table 5 we define it differently to see how the results change and in what way. The definition we use is the same as the performance pay job definition used in Lemieux, MacLeod, and Parent (2009). In that paper we defined performance pay jobs as employment relationships in which workers report receiving either a bonus and/or being on commissions or piece rates at least once over the course of that employment relationship. On one dimensionthe bonus pay-that definition is similar to the one we chose initially. However, we would expect that the presence of commissions and/or piece rates would make a difference in the estimated relationships between DOT characteristics and the probability of being in a complex exchange job as defined by our performance pay job dummy. We view jobs in which commissions or piece rates are paid as not being complex in the sense of being associated with non-routine cognitive-interactive tasks-essentially direction, control, and planning of the firm's activities.

As we can see, while it is still true that job characteristics are related to whether a worker is in a performance pay job, the types of DOT characteristics that are associated with such jobs are not the same as in our base case. In fact, there is little evidence that non-routine cognitive-interactive are related to being in a performance pay job while we find a robust relationship between the measure of routine cognitive tasks and performance pay jobs. Recall that the DOT definition of such tasks is "adaptability to situations requiring the precise attainment of set limits, tolerances, or standards". It is interesting to note that this relationship is entirely dependent on performance pay jobs including commissions and piece rates, forms of pay where one would expect to be associated with the DOT definition of what are routine cognitive tasks. If we keep only bonuses, the relationships reverts largely to what we show in Tables 3 and 4.

In summary, these results provide evidence that the lens of transactions cost economics can provide insight into the form of compensation. Firms vary the way they compensate individuals as a function of the characteristics of the service provided by workers.

\subsection{Hourly Earnings and Complex Exchange}

In this section we look at two related questions. We first examine whether workers in complex exchange jobs are paid more than in other jobs. We then investigate the question of how much do hourly earnings change when workers transit from job to job. More specifically we look at the following types of transitions: 1) from complex exchange to the market, 2) transiting from normal jobs to the market; 3) from the market to complex exchange jobs; and 4) transiting from the market to non-complex exchange jobs. 
This is consistent with the way we think about labor market transitions going back to the work of Jovanovic (1979). The alternative for a worker in a relationship is any alternative job. Thus, we do not constrain the data to require jobs transitions to a particular type. Rather, consistent with the assumption in transactions cost economics that parties "economize", we suppose that when separation occurs workers find the best alternative match, with the form of compensation depending upon the characteristics of the service supplied and not the identity of the worker per se.

In Table 6, we report the estimates from a simple regression of wages on a dummy for complex exchange, including controls for the job characteristics in addition to the usual socio-demographic controls. We can see that there is strong evidence of positive selection into complex exchange as the coefficients estimated with fixed-effects are considerably smaller than those estimated by OLS. Still, even after controlling for unmeasured worker characteristics there is a statistically significant difference in hourly earnings of about $3.5 \%$. Interestingly, whether we control for the task content DOT variables or not does not affect the wage gap even though those variables are statistically associated with wage variations.

It is worth recalling that normal jobs are typically wage labor for which workers are carefully metered. In the case of complex exchange the wage is computed using a worker's self-reported hours of work. Given that it is performance, and not hours of work that is being rewarded, these significant effects can easily be due to an under reporting of hours worked in complex exchange. The alternative explanation is that there is a compensating differential for these jobs. In either case, the evidence is not supportive of an "efficiency wage" effect for normal jobs relative to complex exchange.

We can obtain some further insight into this issue by trying to identify whether such a wage differential is present at the start of the employment relationship or instead is minimal at the start and then builds up over the course of that employment relationship. To investigate this question we look at how a worker's wage changes following a transition from one firm to another.

The results are reported in Table 7 where we show the results both for all workers irrespective of whether the separation is a quit or a layoff, and separately. Note that the estimates reported in each column of lines 1 and 2 in Table 7 come from one regression while the estimates reported in lines 3 and 4 are produced from another. For example in column [1], where there is no control variable (and no constant since the two dummies in lines 1 and 2 are mutually exclusive), the estimates in lines 1 and 2 simply represent the raw log wage change between the last time a worker is observed in one employment relationship and the first time he is observed in the next one, irrespective of what type the next job is. Focusing first on the estimates without controls, a conservative way to interpret the results 
is that there is some evidence of a wage loss when ones transits out of a complex exchange job. However it is not statistically different from the wage change when a worker leaves a non-complex exchange job. Adding controls for tenure, year effects, and the interaction of tenure makes it harder to interpret the coefficients estimates on their own although adding those controls makes little difference to the conclusion that there is no difference between the two types of transitions.

Turning to lines 3 and 4 in Table 7 , we look at the transition from what we call "the market", meaning that we combine all previous jobs irrespective of whether they were complex exchange jobs or not, to either complex exchange jobs or non-complex exchange jobs. Although the estimates are again fairly imprecise, we find no evidence that workers in complex exchange jobs earn more than in other jobs at the start of the employment relationship.

It is important to point out that using wage changes to infer if workers earn rents or not, either at the end of the previous relationship (lines 1 and 2) or at the start (lines 3 and 4) is problematic. The end of an employment relationship is not an exogenous event, nor is the type of jobs workers transit to following displacement in the previous one. The results in Table 6 suggest that there is a wage premium to working in a complex exchange job, although here again, even in fixed-effects models the results are identified from the movement across job types within individuals. While conditioning out unmeasured worker characteristics is certainly an improvement over simple OLS regressions, it still leaves out the problem of endogenous job switches.

Overall the results are consistent with the standard hypothesis in labor economics that wages reflect a worker's skill. There is little evidence that wage levels per se are being used to provide incentives. This does not mean that there are no rents. Central to Williamson et al. (1975)'s theory is that there are significant relation-specific rents. If so we would observe these in terms of the turnover rates.

\subsection{Job Attachment}

The theory of efficient matching does not rely upon wages. Rather, if a relationship is more valuable, then it should face a lower probability of termination, regardless of compensation form. In Table 2 we saw that average tenure is longer in complex exchange jobs than in non-complex exchange jobs. In this sub-section we investigate in more detail whether the difference in job duration reported in the descriptive statistics holds up once we incorporate observed and unobserved heterogeneity.

To do so we estimate a so-called "grouped-data"-or discrete-hazard model which allows for time-varying covariates. Essentially, such a model accounts for the fact that while the 
underlying process generating employment duration is continuous, the data is not recorded in continuous format. To incorporate time-varying covariates we follow Jenkins (1995) and "split" employment spells into yearly observations. Covariates are thus allowed to vary across those observations but they are considered fixed within them. Finally we allow for a flexible (piece-wise constant) baseline hazard as well as unmeasured worker heterogeneity modeled as a Gamma distribution, following (Meyer (1990)). ${ }^{9}$

The results are reported in Table 8 in hazard ratio format. A ratio of less than one associated with an explanatory variable means that the regressor reduces the hazard rate out of the employment relationship. We can see that whether we control for unobserved heterogeneity or not, the qualitative conclusion is basically left unchanged: workers in complex exchange jobs are much less likely to see the employment relationship being terminated (whether by a layoff or a quit) than workers in other jobs. In other words, the results are not supportive of a simple selection story by which more productive workers who are selected into complex exchange jobs also happen to be "low-mobility types".

In Table 8 we also look at how local labor market conditions may affect the hazard out of employment differently in complex vs. non-complex exchange jobs. We use the unemployment rate in the county of residence as a measure of local labor market conditions. Note first that as the local unemployment rate increases, the probability that the job ends increases. This is true whether we control for unobserved heterogeneity or not. Of course, at some level this is not very surprising as part of the relationship has to be basically mechanical if workers sampled in a given county are representative of the population. What is more interesting is the fact that workers in complex exchange jobs are affected to a lesser degree than workers in non-complex exchange jobs, as represented by the smaller-than-one odds ratio associated to the interaction between the local unemployment rate and the complex exchange job indicator. This is quite strong evidence that there is greater relation-specific investment into complex versus normal exchange.

\section{Conclusion}

In this paper we have integrated the effect of transactions costs into a dynamic contract model of employment. The model highlights the many interlocking components of an effective employment relationship. Specifically, the employment contract affects the level of relation-specific investment by both parties, the quality of the goods produced, and finally the conditions under which the relationship continues. We show that one element of trans-

\footnotetext{
${ }^{9}$ We also modeled unobserved heterogeneity using the non-parametric methodology proposed in Heckman and Singer (1984). The results were qualitatively identical.
} 
actions costs concerns the pattern of cost and rewards from a relationship. Normal goods have a well defined performance standard, which if breached leads to employee dismissal. In that case the optimal contract entails a fixed wage combined with employment at will. In contrast, complex exchange is characterized by the difficulty to predict performance by the worker. In this case, the employment contract is characterized by bonus pay, with the threat to leave providing an incentive to the firm to treat the worker fairly.

This perspective allows us to divide jobs in the US into two groups, roughly corresponding to normal and complex exchange. We find that DOT variables that can be interpreted as measures of job complexity are associated with the use of bonus pay. We also find that there is more job security in bonus pay jobs, however we find mixed evidence of rents. This suggests that there is little direct evidence of efficiency wage effects - workers receiving rents to ensure performance. Rather, the results are consistent with the importance of a combination of relation-specific investment, and heterogeneity in transactions costs that lead firms to choose different forms of compensation. This work adds to a growing empirical literature on buyer-seller relationships. Here, we find that the combination of transactions costs, and problems of contract enforcement can help explain observed contracting practices.

\section{References}

Abreu, D., P. Milgrom, and D. Pearce (1991, November). Information and timing in repeated partnerships. Econometrica 59(6), 1713-1734.

Ackerberg, D. A. and M. Botticini (2002). Endogenous matching and the empirical determinants of contract form. The Journal of Political Economy 110(3), 564-591.

Alchian, A. and H. Demsetz (1972, December). Production, information costs, and economic organization,. American Economic Review 62(5), 777-795.

Autor, D. H., F. Levy, and R. J. Murnane (2003, Nov). The skill content of recent technological change: An empirical exploration. Quarterly Journal of Economics 118(4), 1279-1333.

Becker, G. (1962, October). Investment in human capital: A theoretical analysis. Journal of Political Economy 70, 9-49.

Card, D. (1999). The causal effect of education on earnings. In O. Ashenfelter and D. Card (Eds.), Handbook of Labor Economics, Volume 3, pp. 1801-1863. Amsterdam: NorthHolland. 
Gibbons, R. (1997). Incentives and careers in organizations. In D. M. Kreps and K. F. Wallis (Eds.), Advances in Economics and Econometrics: Theory and Applications, pp. 1-37. Cambridge, UK: Cambridge University Press.

Grossman, S. J. and O. D. Hart (1981). Implicit contracts, moral hazard,unemployment. American Economic Review 71 (2), 301-307.

Hall, R. E. and E. P. Lazear (1984, April). The excess sensitivity of layoffs and quits to demand. Journal of Labor Economics 2(2), 233-257.

Hashimoto, M. (1981, June). Firm specific capital as a shared investment. American Economic Review 71(3), 475-482.

Heckman, J. J. and B. Singer (1984, March). A method for minimizing the impact of distributional assumptions in econometric models for duration data. Econometrica 52, 271-320.

Holmes, O. W. (1897, Mar. 25). The path of the law. Harvard Law Review 10(8), 457-478.

Holmström, B. and P. Milgrom (1991). Multi-task principal-agent analyses: Incentive contracts, asset ownership, and job design. Journal of Law, Economics, and Organization 7, $24-52$.

Jenkins, S. P. (1995, Feb). Easy estimation methods for discrete-time duration models. Oxford Bulletin of Economics and Statistics 57(1), 129-138.

Jovanovic, B. (1979). Job matching and the theory of turnover. Journal of Political Economy 87, 972-90.

Kerr, S. (1975, December). On the folly of rewarding A, while hoping for B. Academy of Management Journal 18(4), 769-783.

Kornhauser, L. and W. B. MacLeod (2012). Contracts between legal persons. In R. Gibbons and J. Roberts (Eds.), Handbook of Organizational Economics, Chapter 23. Princeton University Press.

Lafontaine, F. and M. Slade (2011). Inter-firm contracts. In R. Gibbons and J. Roberts (Eds.), Handbook of Organizational Economics. Princeton University Press.

Lemieux, T., W. B. MacLeod, and D. Parent (2009, February). Performance pay and wage inequality. Quarterly Journal of Economics 124(1), 1-49. 
Lemieux, T., W. B. MacLeod, and D. Parent (2012, May). Contract form, wage flexibility and employment. American Economic Review 101 (3).

MacLeod, W. B. (2007, September). Reputations, relationships and contract enforcement. Journal of Economics Literature XLV, 597-630.

MacLeod, W. B. and J. M. Malcomson (1989, March). Implicit contracts, incentive compatibility, and involuntary unemployment. Econometrica 57(2), 447-480.

MacLeod, W. B. and J. M. Malcomson (1993, September). Investments, holdup, and the form of market contracts. American Economic Review 83(4), 811-837.

MacLeod, W. B. and D. Parent (1999). Job characteristics and the form of compensation. Research in Labor Economics 18, 177-242.

Mellow, W. and H. Sider (1983). Accuracy of response in labor market surveys: Evidence and implications. Journal of Labor Economics 1, 331-344.

Meyer, B. (1990, July). Unemployment insurance and unemployment spells. Econometrica $58,757-782$.

Mincer, J. (1958). Investment in human-capital and personal income-distribution. Journal of Political Economy 66(4), 281-302.

Myerson, R. B. and M. A. Satterthwaite (1983). Efficient mechanisms for bilateral trading. Journal of Economic Theory 29, 265-281.

Prendergast, C. (1999, March). The provision of incentives in firms. Journal of Economic Literature 37(1), 7-63.

Prendergast, C. (2002, October). The tenuous trade-off between risk and incentives. Journal of Political Economy 110(5), 1071-1102.

Shapiro, C. and J. E. Stiglitz (1984, June). Equilibrium unemployment as a worker discipline device. American Economic Review 74(3), 433-444.

Slade, M. E. (1996, May). Multitask agency and contract choice: An empirical exploration. International Economic Review 37(2), 465-486.

Taylor, F. W. (1911). The principles of scientific management. New York; London: Harper. by Frederick Winslow Taylor ... $23 \mathrm{~cm}$. 
Williamson, O. E. (1985). The Economic Institutions of Capitalism. New York: The Free Press.

Williamson, O. E. (2002, Sum). The theory of the firm as governance structure: From choice to contract. Journal of Economic Perspectives 16(3), 171-195. Review.

Williamson, O. E., M. L. Wachter, and J. E. Harris (1975, Spring). Understanding the employment relation: the analysis of idiosyncratic exchange. Bell Journal of Economics 6(1), $250-278$.

\section{A Appendix}

\section{A.1 Derivation of Optimal Matching and Investment Rules}

Let $\alpha=v\left(q^{*}\right)+u^{s}(i)$ be the non-random component of the per period flow returns. We can write the payoff from a match as:

$$
\begin{aligned}
S\left(u_{t}, v_{t}, \alpha\right) & =\max _{e_{t} \in\{0,1\}} e_{t}\left\{\left(v_{t}+\alpha\right) \Delta+\delta E\left\{S\left(u_{t+1}, v_{t+1}, \alpha\right)\right\}\right\} . \\
& +\left(1-e_{t}\right)\left\{u_{t} \Delta+\delta \bar{u} / r\right\}
\end{aligned}
$$

At the beginning of period t parties optimally decide whether to continue or not. We have assumed that the payoff in the period and the outside option are i.i.d. random variables. This implies that the expected surplus before the realization of the flows is the same each period. Hence, if the value function exists, then we can define the optimal ex ante surplus as a function of $\alpha$ by:

$$
S^{*}(\alpha)=E\left\{S\left(u_{t}, v_{t}, \alpha\right)\right\}
$$

We will show that this function is the unique solution to a fixed point problem, from which we can derive the function $S\left(u_{t}, v_{t}, \alpha\right)$ using 14 .

The expected value of leaving a relationship for a worker is $\bar{u} / r$, where $\bar{u}$ is the mean of the distribution of outside options. To solve for the value function, we take $\alpha$ as fixed, and then solve for the value function given $S^{*}$. We then find $S^{*}$ as the solution to a fixed point problem, which will also yield dependence upon $\alpha$. 
Given $S^{*}$, the worker and firm stay matched whenever:

$$
\begin{aligned}
\left(v_{t}+\alpha\right) \Delta+\delta S^{*} & \geq u_{t} \Delta+\delta \frac{\bar{u}}{r}, \\
v_{t}-u_{t} & \geq \delta\left(\frac{\bar{u}}{r}-S^{*}\right) / \Delta-\alpha .
\end{aligned}
$$

Let $\Omega^{E}\left(S^{*}, \alpha\right)$ be the set of $\left(v_{t}, u_{t}\right)$ that satisfy 16 , and let the set of states where there is separation be given by:

$$
\Omega^{0}\left(S^{*}, \alpha\right)=\Re_{++}^{2}-\Omega^{E}\left(S^{*}, \alpha\right)
$$

We can now compute the expected value of continuation with optimal matching:

$$
\begin{gathered}
F\left(S^{*}, \alpha\right)=\int_{(u, v) \in \Omega^{E}\left(S^{*}, \alpha\right)}\left(v_{t}+\alpha\right) \Delta+\delta S^{*} f_{u}(u) f_{v}(v) d u d v \\
+\int_{(u, v) \in \Omega)\left(S^{*}, \alpha\right)} u_{t} \Delta+\delta \bar{u} / r f_{u}(u) f_{v}(v) d u d v
\end{gathered}
$$

where $f_{u}$ and $f_{v}$ are the $\log$ normal densities for realizations of $u_{t}$ and $v_{t}$.

This function is clearly an increasing function of $S^{*}$ and $\alpha$ with the properties that $F(0, \alpha)>0$ and $\partial F / \partial S^{*}<1$, hence there exists a unique solution:

$$
S^{*}(\alpha)=F\left(S^{*}(\alpha), \alpha\right)
$$

The final step requires determining the optimal level of relation-specific investment by the worker. The probability that a relationship continues at the end of the period is given by:

$$
\rho(\alpha)=\operatorname{Prob}\left\{\Omega^{E}\left(S^{*}(\alpha), \alpha\right)\right\},
$$

which is a continuous and increasing function of $\alpha$.

Thus the present value of the relation specific invesment is given by:

$$
U^{S}(i)=\rho\left(v\left(q^{*}\right)+u^{s}\left(i^{*}\right)\right)\left(u^{s}\left(i^{*}\right)+\delta U^{S}(i)\right)
$$

The result is:

$$
U^{S}(i)=u^{s}(i) \frac{\Delta}{1-\delta \rho\left(v\left(q^{*}\right)+u^{s}\left(i^{*}\right)\right)} .
$$

The net benefit from a relation-specific investment is $U^{S}\left(u^{s}, i\right)-i$. Hence this optimal level of investment is the solution to:

$$
d u^{s}(i) / d i=\frac{1-\delta \rho\left(v\left(q^{*}\right)+u^{s}\left(i^{*}\right)\right)}{\Delta}>0 .
$$


Notice we do not have a term that includes the derivative of $\rho$. The reason for this is that the marginal effect on the payoff is zero via the envelope theorem. The probability of separation is due to the optimal choice between a match and a quit. A small change in the boundary between a match and no match has no effect because the payoff is the same on each side.

The left hand side is monotonically decreasing with $i$, while the right hand side is increasing, hence if a solution exists it is unique. If $d u^{s}(0) / d i<\frac{1-\delta \rho\left(v\left(q^{*}\right)\right)}{\Delta}$, then the only equilibrium is no investment. Notice that a change in parameters resulting in an increase in the probability of a match increases specific investments by the worker. 


\section{B Tables}

Table 2. Summary Statistics: Panel Study of Income Dynamics 1976-2004

\begin{tabular}{|c|c|c|}
\hline & $\begin{array}{l}\text { Non Complex } \\
\text { Exchange Jobs }\end{array}$ & $\begin{array}{c}\text { Complex } \\
\text { Exchange Jobs }\end{array}$ \\
\hline Routine manual & 0.06 & -0.24 \\
\hline Non-routine manual & 0.15 & -0.49 \\
\hline Routine cognitive & 0.09 & -0.19 \\
\hline Non-routine cognitive/interactive & -0.28 & 0.83 \\
\hline Non-routine cognitive/analytical & -0.18 & 0.55 \\
\hline Average Hourly Earnings $(\$ 79)$ & 7.94 & 11.98 \\
\hline Education & 12.30 & 14.32 \\
\hline Potential Experience & 20.16 & 20.92 \\
\hline Employer Tenure & 7.52 & 9.30 \\
\hline Married & 0.71 & 0.78 \\
\hline Unionized & 0.30 & 0.04 \\
\hline Non White & 0.15 & 0.07 \\
\hline Fraction Unemployed at Interview & 0.068 & 0.008 \\
\hline Annual Hours Worked & 2076.3 & 2263.7 \\
\hline \# workers (Tot:3090) & 2590 & 1289 \\
\hline \# Job Matches (Tot: 8911) & 6780 & 2131 \\
\hline \# Observations (Tot: 28415) & 19650 & 8765 \\
\hline
\end{tabular}

Notes: The sample consists of male household heads aged 18-65 working in private sector, wage and salary jobs. All figures in the table represent sample means. Education, potential experience, and employer tenure are measured in years. Potential experience is defined as age minus education minus 6 . See text for the definition of a complex job. All Dictionary of Occupational Titles task content variables are standardized with mean zero and unit variance. Temporarily laid off workers are included among the unemployed. 


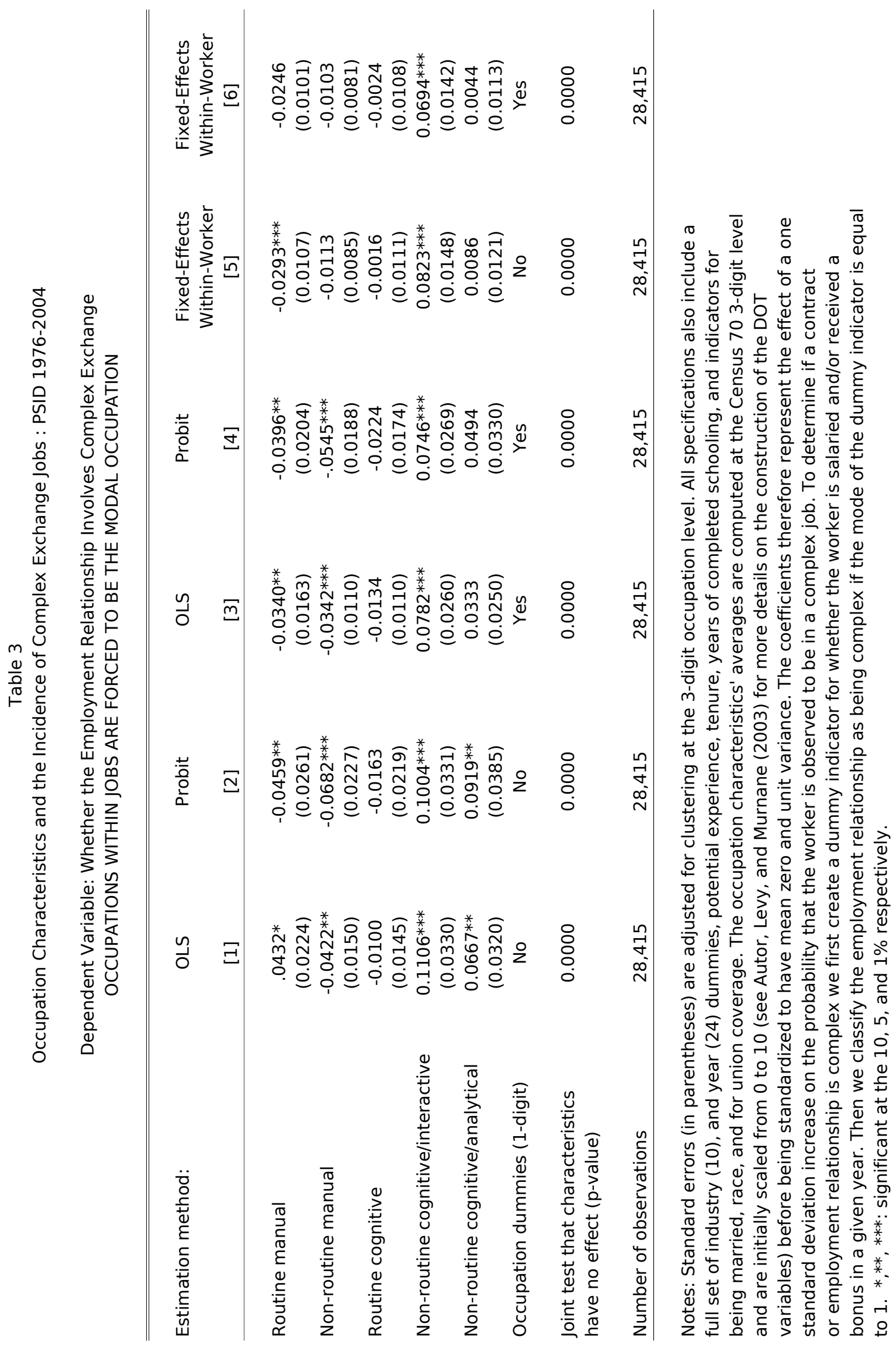




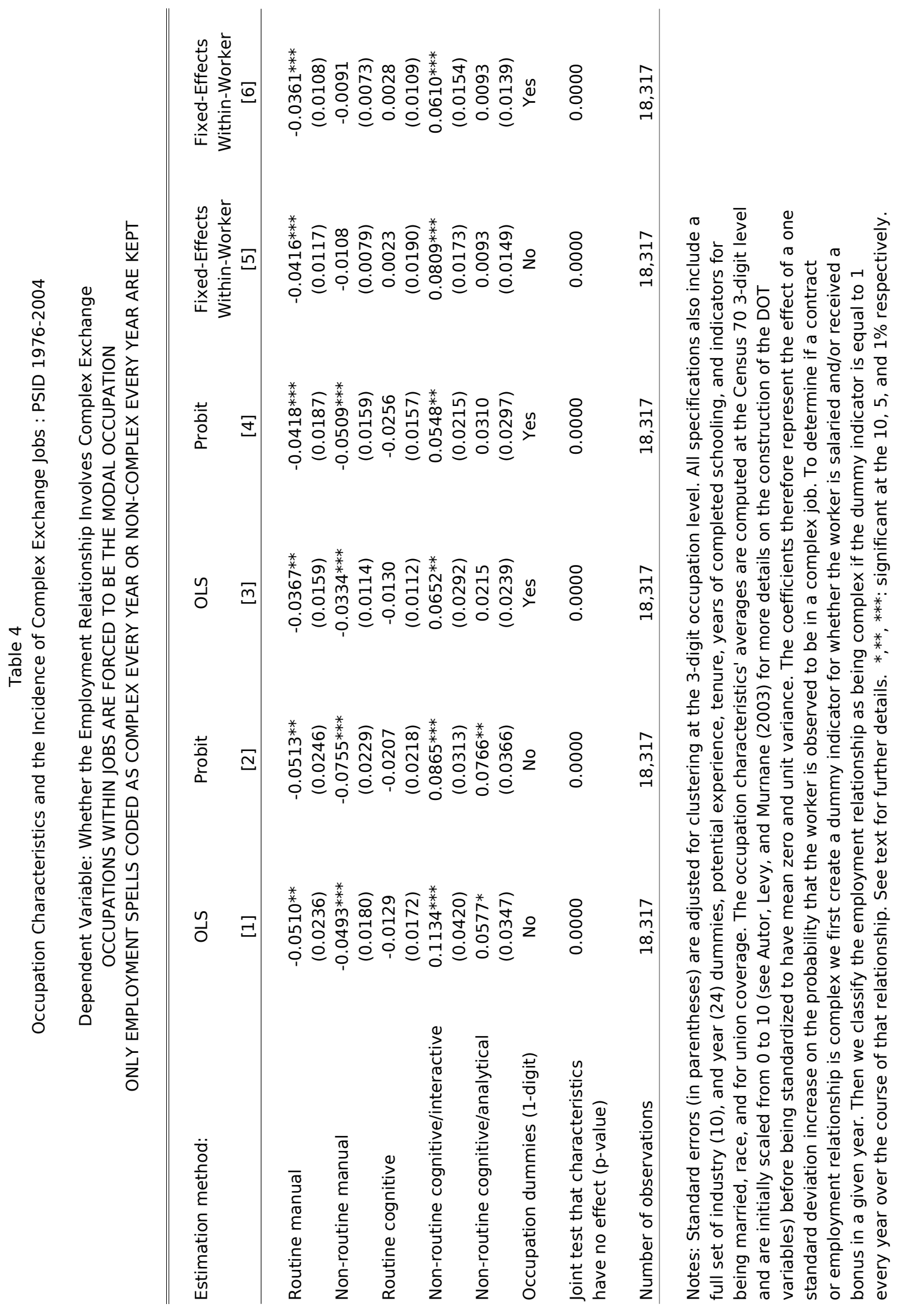




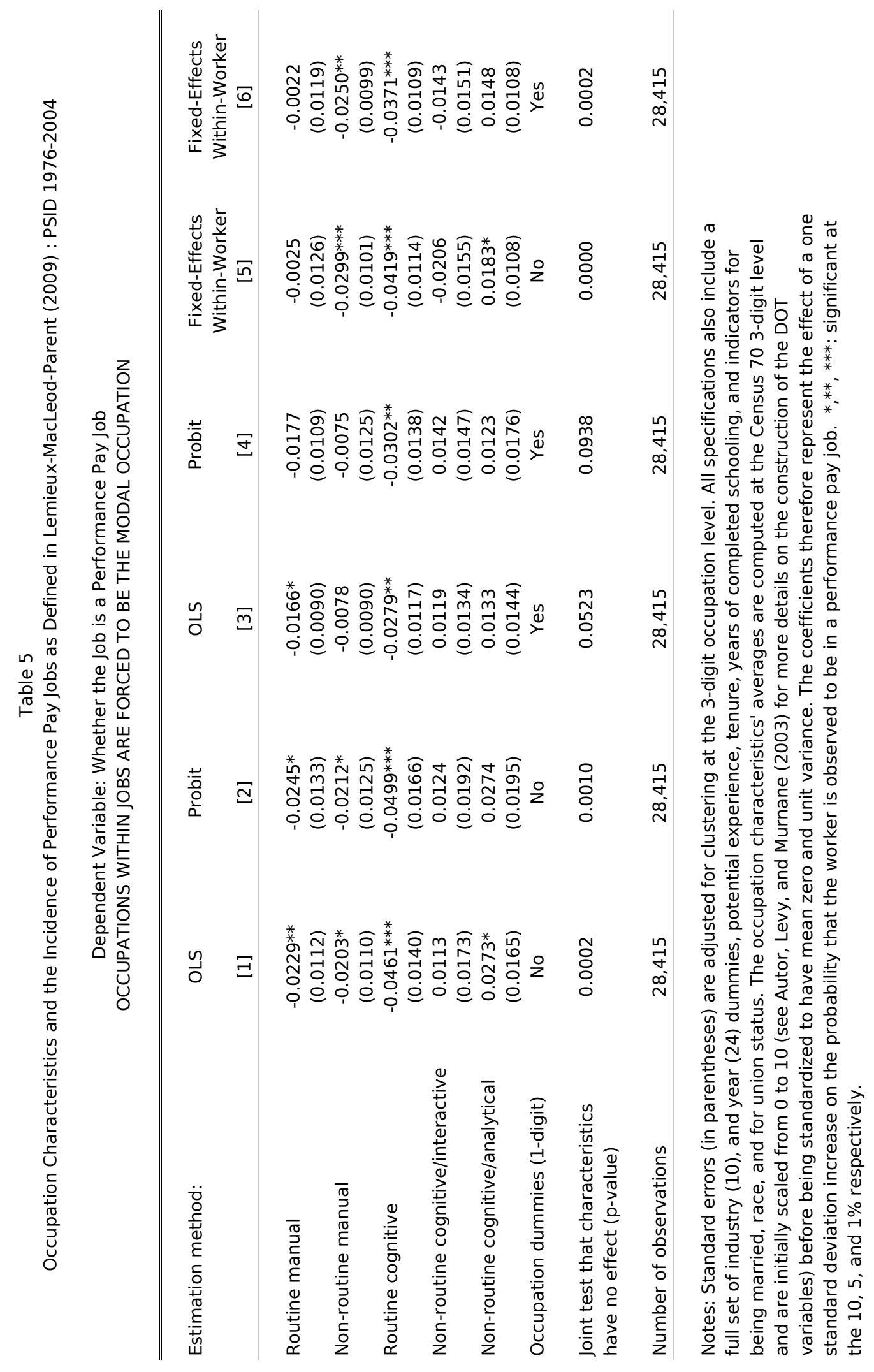


Table 6

Regression Estimates of the Effect of Being in a Complex Exchange Job on Log Average Hourly Earnings

\begin{tabular}{|c|c|c|c|c|}
\hline \multirow[t]{2}{*}{ Estimation method: } & \multicolumn{2}{|c|}{ OLS } & \multicolumn{2}{|c|}{ Fixed effects } \\
\hline & [1] & {$[2]$} & [3] & [4] \\
\hline Complex exchange job & $\begin{array}{c}0.1130 * * * \\
(0.0188)\end{array}$ & $\begin{array}{c}0.1095^{* * *} \\
(0.0193)\end{array}$ & $\begin{array}{c}0.0363^{* * *} \\
(0.0084)\end{array}$ & $\begin{array}{c}0.0364 * * \\
(0.0085)\end{array}$ \\
\hline Routine manual & - & $\begin{array}{c}0.0089 \\
(0.0082)\end{array}$ & - & $\begin{array}{c}0.0093^{* * *} \\
(0.0036)\end{array}$ \\
\hline Non-routine manual & - & $\begin{array}{c}0.0194 \\
(0.0100)\end{array}$ & - & $\begin{array}{c}0.0114 * * * \\
(0.0042)\end{array}$ \\
\hline Routine cognitive & - & $\begin{array}{c}0.0040 \\
(0.0087)\end{array}$ & - & $\begin{array}{c}-0.0079 * * \\
(0.0037)\end{array}$ \\
\hline Non-routine cognitive/interactive & - & $\begin{array}{c}0.0118 \\
(0.0115)\end{array}$ & - & $\begin{array}{c}0.0026 \\
(0.0047)\end{array}$ \\
\hline Non-routine cognitive/analytical & - & $\begin{array}{c}0.0429 * * * \\
(0.0105)\end{array}$ & - & $\begin{array}{c}0.0262 * * * \\
(0.0085)\end{array}$ \\
\hline Worker fixed effect & No & No & Yes & Yes \\
\hline
\end{tabular}

Notes. 28,415 observations. Standard errors (in parentheses) are adjusted for clustering at the worker level level. All specifications also include a full set of industry (10), occupations (8), and year (22) dummies, a cubic in potential experience, a quadratic in job tenure, years of completed schooling, and dummies for being married, nonwhite, and for union status. To determine if a contract or employment relationship is complex we first create a dummy indicator for whether the worker is salaried and/or received a bonus in a given year. Then we classify the employment relationship as being complex if the mode of the dummy indicator is 1 over the course of that relationship. See text for further details. *,**, ***: significant at the 10,5 , and $1 \%$ respectively. 


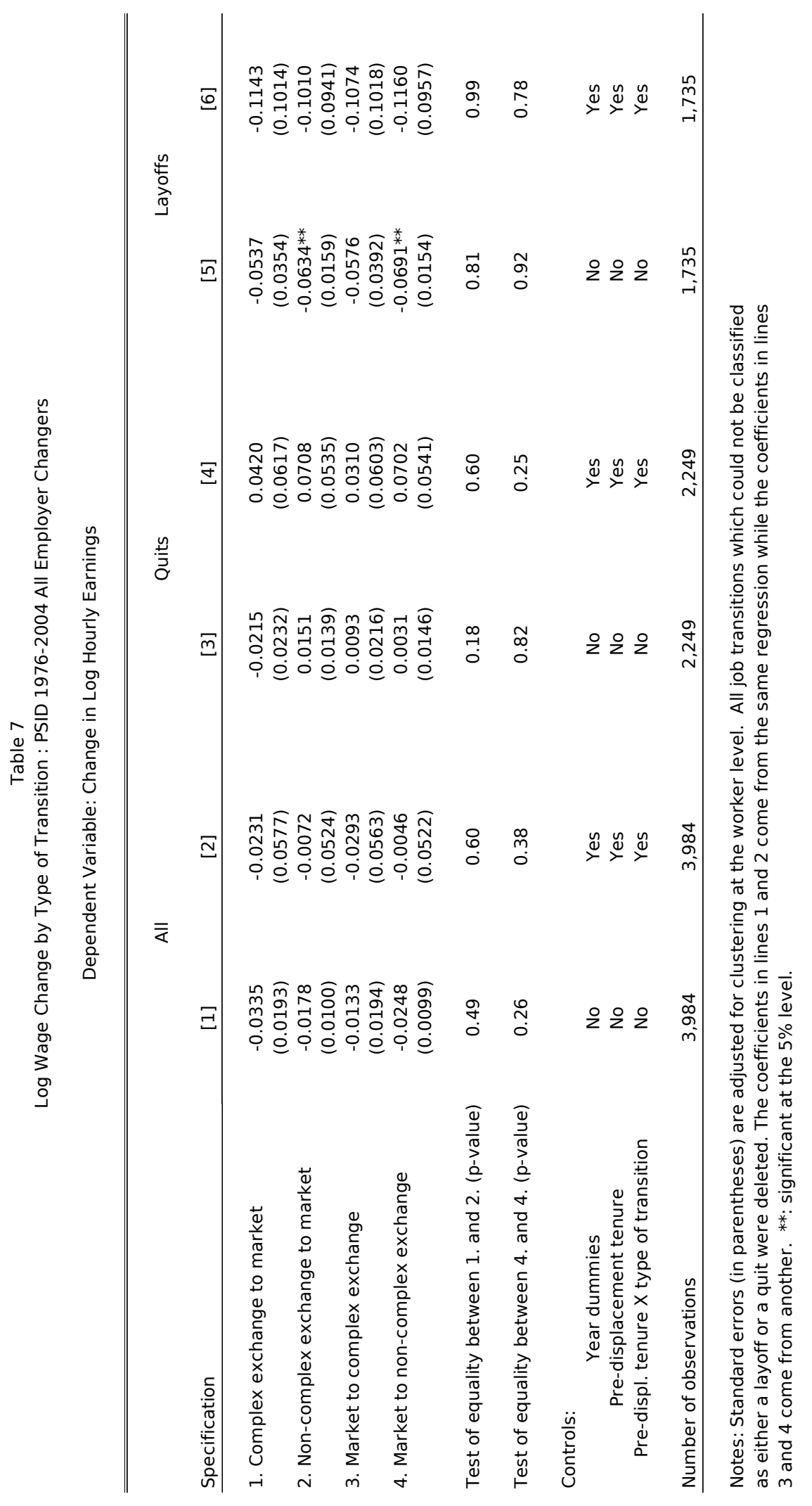


Table 8. Grouped-Data Hazard Model Estimates

\begin{tabular}{|c|c|c|c|c|}
\hline Variable & Without Cor & terogeneity & With Con & rogeneity \\
\hline Complex exchange job & $\begin{array}{l}0.777^{* * *} \\
(0.024)\end{array}$ & $\begin{array}{l}.862 * * \\
(0.058)\end{array}$ & $\begin{array}{l}0.750 * * * \\
(0.029)\end{array}$ & $\begin{array}{l}.851 * * \\
(0.068)\end{array}$ \\
\hline $\begin{array}{l}\text { Unemployment rate } \\
\text { in county of residence }\end{array}$ & - & $\begin{array}{l}1.016 * * * \\
(0.005)\end{array}$ & - & $\begin{array}{l}1.02 * * * \\
(0.006)\end{array}$ \\
\hline Unemp. rate $X$ complex exchange job & & $\begin{array}{l}0.984^{*} \\
(0.009)\end{array}$ & & $\begin{array}{l}0.980 * \\
(0.011)\end{array}$ \\
\hline Potential experience & $\begin{array}{c}0.989 \\
(0.008)\end{array}$ & $\begin{array}{c}0.988 \\
(0.008)\end{array}$ & $\begin{array}{c}0.994 \\
(0.010)\end{array}$ & $\begin{array}{c}0.995 \\
(0.010)\end{array}$ \\
\hline Education & $\begin{array}{c}1.008 \\
(0.006)\end{array}$ & $\begin{array}{c}1.008 \\
(0.006)\end{array}$ & $\begin{array}{c}1.007 \\
(0.008)\end{array}$ & $\begin{array}{c}1.008 \\
(0.008)\end{array}$ \\
\hline Covered by CBA & $\begin{array}{l}0.644 * * * \\
(0.022)\end{array}$ & $\begin{array}{l}0.642 * * * \\
(0.022)\end{array}$ & $\begin{array}{l}0.599 * * * \\
(0.025)\end{array}$ & $\begin{array}{c}0.599 * * * \\
(0.025)\end{array}$ \\
\hline Married & $\begin{array}{l}0.740 * * * \\
(0.018)\end{array}$ & $\begin{array}{c}0.739 * * * \\
(0.018)\end{array}$ & $\begin{array}{c}0.728^{* * *} \\
(0.021)\end{array}$ & $\begin{array}{c}0.726 * * * \\
(0.021)\end{array}$ \\
\hline Nonwhite & $\begin{array}{l}1.053^{* *} \\
(0.027)\end{array}$ & $\begin{array}{c}1.050 * \\
(0.027)\end{array}$ & $\begin{array}{l}1.059 * * \\
(0.034)\end{array}$ & $\begin{array}{c}1.062 * \\
(0.034)\end{array}$ \\
\hline Industry dummies & Yes & Yes & Yes & Yes \\
\hline Occupation dummies & Yes & Yes & Yes & Yes \\
\hline Year dummies & Yes & Yes & Yes & Yes \\
\hline $\begin{array}{l}\text { - Log likelihood } \\
\text { LR test of zero gamma variance } \\
\text { [p-value] }\end{array}$ & $\begin{array}{c}14961.2 \\
-\end{array}$ & $\begin{array}{c}14956.5 \\
-\end{array}$ & $\begin{array}{c}14822.0 \\
278.3 \\
{[0.0000]}\end{array}$ & $\begin{array}{c}14812.7 \\
287.6 \\
{[0.0000]}\end{array}$ \\
\hline
\end{tabular}

The parameter estimates are the exponentiated coefficients and thus represent the hazard ratio. *, **, ***: significant at the 10,5 and $1 \%$ level, respectively. Worker heterogeneity is modelled using a gamma distribution function while the baseline hazard is estimated as being piece-wise constant using interval-specific dummy variables (9 intervals). 